population growth is likely to be in smaller cities and towns, whose capabilities for planning and implementation can be exceedingly weak'. ${ }^{1}$

The fourth message is that successfully responding to the future challenges and opportunities of urbanisation will require a range of actions such as:

- a shift towards healthy public policy increasing the capacity of the health sector to engage intersectorally on urban planning

- understanding the regulatory framework that governs urban planning in NSW

- learning from past lessons concerning advocating for health as part of urbanisation and

- building on the strengths of, and meeting the challenges set by, HIA in NSW to date.

At all levels of the urbanisation debate - global, national and local, it is apparent that health must become actively engaged in order to enhance the sustainability of planning activities. HIA is now established as one tool to facilitate that engagement. This issue of the Bulletin shows that NSW is now in a position, as a world leader on HIA, to support the pivotal future role that urbanisation will play in influencing the health of populations and communities.

\section{References}

1. UNFPA. State of the world population 2007: unleashing the potential of urban growth. United Nations Population Fund. At http://www.unfpa.org/swp/, accessed 13 August 2007.

2. Australian Bureau of Statistics. Year Book Australia 2007. Canberra: Australian Bureau of Statistics, 2007.

3. NSW Government State Plan: a new direction for NSW. Sydney: Premier's Department of Health, 2007.

4. Harris-Roxas B, Simpson S. The NSW Health Impact Assessment Project. N S W Public Health Bull 2005; 16(7-8): 120-3.

5. Capon AG, Dixon JM. Cities, sustainability and health (special edition). N S W Public Health Bull 2007; 18(3-4): 37-72.

\title{
Influencing urban environments for health: NSW Health's response
}

\section{EDITORIAL}

\section{Sarah V. Thackway ${ }^{\mathrm{A}, \mathrm{C}}$, Andrew J. Milat ${ }^{\mathrm{B}}$ and Elizabeth Develin ${ }^{\mathrm{B}}$}

${ }^{\mathrm{A} C e n t r e ~ f o r ~ E p i d e m i o l o g y ~ a n d ~ R e s e a r c h, ~}$

NSW Department of Health

${ }^{\mathrm{B}}$ Centre for Chronic Disease Prevention and Health Advancement, NSW Department of Health

${ }^{\mathrm{C}}$ Corresponding author. Email:

sarah.thackway@doh.health.nsw.gov.au

The burden of preventable chronic disease is rapidly increasing in New South Wales. ${ }^{1}$ If the potential for preventing chronic diseases is not fully harnessed, it is projected that treatment costs alone for people with diabetes, cardiovascular disease, cancers and musculoskeletal conditions in NSW will rise from approximately $\$ 3.3$ billion in $2000-01$ to $\$ 6.1$ billion by $2020-21 .^{2}$ Addressing this challenge will require a multifactorial approach and there is a growing body of evidence around the links between risk factors apportioned to increasing urbanisation and, more broadly, to the built environment. ${ }^{3-5}$ Creating environments that promote health can play a significant role in reducing rates of death and disability from chronic disease ${ }^{6}$ Compounding the challenge of addressing potentially avoidable chronic diseases is the sustainability of our urban communities, with increasing populations in and around Sydney and coastal NSW in particular. For example, over the next 20 years, population increases of over $50 \%$ are expected in several coastal townships. ${ }^{7}$

The importance of urban planning for health has been identified as a key priority for the NSW Government as described in the: NSW State Plan, ${ }^{8}$ NSW State Health Plan, ${ }^{9}$ Healthy People NSW, ${ }^{10}$ and the NSW Population Health Priority Taskforce. In particular, Healthy People $N S W$ identifies health impact assessment (HIA) as a key tool for affecting change and to strengthen health input into planning decisions. ${ }^{10}$

While in NSW it is local government planners and urban designers who have the ability to directly influence and shape the urban environment, NSW Health is increasing its engagement at both a state and regional level. This issue of 
the Bulletin reflects the increased level of activity and innovation by Health Services across NSW to influence the shape of the urban environment, through the use of HIA in projects from housing regeneration to population growth to capital works, in line with the growing body of evidence.

For a number of years, NSW Health has invested in and worked towards creating a more cohesive partnership approach to urban planning projects with state and regional planning bodies including the NSW Local Government and Shires Associations, through the NSW Health Impact Assessment Project, and health risk assessment work. The learning-by-doing approach to HIA outlined in this issue highlights the practical impacts on planning that such a tool can have. HIA has emerged as a good mechanism through which to engage with the urban planning sector, as evidenced by the successful implementation of several joint Area Health Services and local government HIA projects in NSW in recent years. An acknowledged leader in this has been the Greater Southern Area Health Service, whose active engagement with the planning sector recently earned them an award from the University of NSW and the NSW HIA Steering Committee.

The coming year sees several activities being conducted in this domain including a statewide review of the activities being undertaken. This review will identify opportunities to build on the successes of recent years and to maximise NSW Health's impact on urban planning and regeneration frameworks. Another highlight will be the 7-9 November 2007 South East Asia and Oceania Regional Health Impact Assessment Conference to be held in Sydney. This will be jointly hosted by NSW Health and the University of NSW Research Centre for Primary Health Care and
Equity. The conference will be an important vehicle to facilitate greater engagement between the health and planning sectors, as well as academia, both in NSW and the South East Asia and Oceania regions.

\section{References}

1. Begg S, Vos T, Barker B, Stevenson C, Stanley L, Lopez A. The burden of disease and injury in Australia 2003. PHE 83. Canberra: AIHW, 2007.

2. Voss T, Goss J, Begg S, Mann N. Australian burden of disease and injury study: projected health care costs report. Brisbane: University of Queensland and Australian Institute of Health and Welfare, In press.

3. Saelens BE, Sallis JF, Frank LD. Environmental correlates of walking and cycling: findings from the transportation, urban design and planning literatures. Ann Behav Med 2003; 25: 80-91. doi:10.1207/S15324796ABM2502_03

4. Ewing R, Schmid T, Killingsworth R, Zlot A, Raudenbush S. Relationship between urban sprawl and physical activity, obesity and morbidity. Am J Health Promot 2003; 18: 47-57.

5. Lopez R. Urban sprawl and the risk for being overweight or obese. Am J Public Health 2004; 94: 1574-9.

6. World Health Organization. Food Agricultural Organization Joint Report. Diet, Nutrition and the Prevention of Chronic Disease. Geneva: WHO, 2002.

7. NSW Health Department. Chief Health Officer's Report. At http://www.health.nsw.gov.au/publichealth/chorep/dem/dem _pop_percentmap.htm, accessed 30 July 2007.

8. NSW Government. State Plan: a new direction for NSW. Sydney: Premier's Department, 2006.

9. NSW Department of Health. State Health Plan towards 2010: a new direction for NSW. North Sydney: NSW Department of Health, 2007.

10. NSW Department of Health. Healthy People NSW. North Sydney: NSW Department of Health, 2007.

\section{South East Asia and Oceania Regional Health Impact Assessment Conference}

The Conference will be held in Sydney, Australia from Wednesday 7 to Friday 9 November 2007 at the Menzies.

This event will bring together health impact assessment (HIA) practitioners from South East Asia and Oceania for the first time. The conference will provide an opportunity for delegates to learn, meet other practitioners, network, share experiences, contribute ideas and to reflect on HIA.

$\mathrm{HIA}$ is a structured process for looking at the positive and negative, intended and unintended impacts that may eventuate from projects, programs or policies. It also considers the distribution of impacts across the population and within affected groups.

For registration information, including an updated conference program, visit the HIA conference website, www.hia2007.com 